\title{
A first genome assembly of the barley fungal pathogen Pyrenophora teres f. teres
} Simon R Ellwood ${ }^{1 *}$, Zhaohui Liu², Rob A Syme ${ }^{1}$, Zhibing Lai ${ }^{2}$, James K Hane ${ }^{3}$, Felicity Keiper ${ }^{4}$, Caroline S Moffat ${ }^{5}$,
Richard P Oliver ${ }^{2}$ and Timothy L Friesen

\begin{abstract}
Background: Pyrenophora teres $\mathrm{f}$. teres is a necrotrophic fungal pathogen and the cause of one of barley's most important diseases, net form of net blotch. Here we report the first genome assembly for this species based solely on short Solexa sequencing reads of isolate $0-1$. The assembly was validated by comparison to BAC sequences, ESTs, orthologous genes and by PCR, and complemented by cytogenetic karyotyping and the first genome-wide genetic map for $P$. teres $f$. teres.

Results: The total assembly was $41.95 \mathrm{Mbp}$ and contains 11,799 gene models of 50 amino acids or more. Comparison against two sequenced BACs showed that complex regions with a high GC content assembled effectively. Electrophoretic karyotyping showed distinct chromosomal polymorphisms between isolates 0-1 and $15 \mathrm{~A}$, and cytological karyotyping confirmed the presence of at least nine chromosomes. The genetic map spans $2477.7 \mathrm{cM}$ and is composed of 243 markers in 25 linkage groups, and incorporates simple sequence repeat markers developed from the assembly. Among predicted genes, non-ribosomal peptide synthetases and efflux pumps in particular appear to have undergone a P. teres $\mathrm{f}$. teres-specific expansion of non-orthologous gene families.

Conclusions: This study demonstrates that paired-end Solexa sequencing can successfully capture coding regions of a filamentous fungal genome. The assembly contains a plethora of predicted genes that have been implicated in a necrotrophic lifestyle and pathogenicity and presents a significant resource for examining the bases for $P$. teres f. teres pathogenicity.
\end{abstract}

\section{Background}

Net blotch of barley (Hordeum vulgare) is caused by Pyrenophora teres Drechsler (anamorph Drechslera teres [Sacc.] Shoem.). P. teres is an ascomycete within the class Dothideomycetes and order Pleosporales. This order contains plant pathogens responsible for many necrotrophic diseases in crops, including members of the genera Ascochyta, Cochliobolus, Pyrenophora, Leptosphaeria and Stagonospora. Net blotch is a major disease worldwide that causes barley yield losses of 10 to $40 \%$, although complete loss can occur with susceptible cultivars in the absence of fungicide treatment [1]. In Australia the value of disease control is estimated at $\$ 246$ million annually with average direct costs of $\$ 62$ million

\footnotetext{
* Correspondence: srellwood@gmail.com

'Department of Environment and Agriculture, Curtin University, Kent Street, Bentley, Perth, Western Australia 6102, Australia

Full list of author information is available at the end of the article
}

annually, making it the country's most significant barley disease [2].

Net blotch exists in two morphologically indistinguishable but genetically differentiated forms: $P$. teres $\mathrm{f}$. teres (net form of net blotch, NFNB) and P. teres f. maculata (spot form of net blotch, SFNB) [3,4]. These forms have been proposed as distinct species based on the divergence of MAT sequences in comparison to Pyrenophora graminea [4]. Additionally, it has been suggested that limited gene flow may occur between the two forms $[5,6]$. As their names indicate, the two forms show different disease symptoms. NFNB produces lattice-like symptoms, in which necrosis develops along leaf veins with occasional transverse striations. SFNB displays more discrete, rounded lesions, often surrounded by a chlorotic zone. NFNB and SFNB may both be present in the same region but with one form prevailing in individual locales. NFNB has historically been regarded as the 
more significant of the two diseases, but in recent years there have been reports of SFNB epidemics, notably in regions of Australia and Canada $[7,8]$.

Only recently have researchers begun to focus on the molecular and genetic aspects of $P$. teres pathogenesis and host-pathogen interactions. NFNB is known to produce non-host selective low molecular weight compounds that cause chlorosis on barley leaves [9]. Both forms also produce phytotoxic proteinaceous effectors in culture $[10,11]$. It has been suggested that these effectors are responsible for the brown necrotic component of the disease symptoms on susceptible cultivars. Host resistance to $P$. teres appears to conform to the genefor-gene model [12]. Both dominant and recessive resistance loci have been reported that are genetically distinct. These are host genotype, form, and isolate specific, and occur along with multigenic/quantitative resistance on each of the barley chromosomes [13,14].

Little is known at the molecular level about the mechanisms of $P$. teres pathogenicity, with neither the mechanism of virulence nor host resistance known. A genome assembly offers a powerful resource to assist the dissection of virulence mechanisms by providing suites of genetic markers to characterize and isolate genes associated with virulence and avirulence via mapbased cloning. It also enables potential effector candidate genes to be identified from partially purified active fractions in conjunction with mass spectrometry peptide analysis. The sequencing and assembly of fungal genomes to date have relied primarily on Sanger sequencing with read lengths of 700 to $950 \mathrm{bp}$. Several newer sequencing technologies are now available that are orders of magnitude less expensive, although currently they exhibit shorter read lengths. These include Roche/ 454 pyrosequencing (400 to $500 \mathrm{bp}$ ) and Illumina/Solexa sequencing (currently up to $100 \mathrm{bp}$ ). Recent improvements, including paired-end sequencing (reads from each end of longer DNA fragments) and continuing increases in read lengths should make the de novo assembly of high quality eukaryotic genomes possible.

Filamentous fungal genomes are relatively small and contain a remarkably consistent number of genes. Their genomes range in size from 30 to $100 \mathrm{Mbp}$ and contain 10,000 to 13,000 predicted genes [15]. Their reduced complexity and small size relative to most eukaryotes makes them amenable to assessing the suitability of new sequencing technologies. These technologies have recently been described in the assembly of the filamentous fungus Sordaria macrospora [16], which involved a hybrid assembly of Solexa 36-bp reads and 454 sequencing. The objectives of this study were to assemble the genome of $P$. teres $\mathrm{f}$. teres based on Solexa sequencing chemistry only, to validate the assembly given the short read lengths (in this study, 75-bp paired ends), and to provide initial characterization of the draft genome. We have complemented the assembly with the first cytogenetic visualization and genome-wide genetic map for this species.

\section{Results}

The genome of $P$. teres $\mathrm{f}$. teres isolate $0-1$ was sequenced using Illumina's Solexa sequencing platform with pairedend 75 -bp reads. The Solexa run in a single flow cell yielded over $833 \mathrm{Mbp}$ of sequence data, or approximately 20 times coverage of the final assembly length. Optimal kmer length in the parallel assembler Assembly By Short Sequences (ABySS) v. 1.0.14 [17] occurred at k $=45$ and $n=5$. This yielded a $\mathrm{N}_{50}$ where $50 \%$ of the assembly is contained in the largest 408 scaffolds and an $\mathrm{L}_{50}$ whereby $50 \%$ of the genome is contained in scaffolds of $26,790 \mathrm{bp}$ or more. The total assembly size was 41.95 Mbp. Summary statistics of the assembly are presented in Table 1.

The Solexa sequencing reads that were used for the $P$. teres $\mathrm{f}$. teres $0-1$ genome assembly have been deposited in the NCBI sequence read archive [GenBank: SRA020836]. This whole genome shotgun project assembly has been deposited at DDBJ/EMBL/GenBank under the accession [GenBank: AEEY00000000]. The version described in this paper [GenBank: AEEY01000000] is the first version. Note NCBI does not accept contigs less than $200 \mathrm{bp}$ in whole genome submissions, unless such sequences are important to the assembly, for example, they contribute to scaffolds or are gene coding regions. In addition, all scaffold nucleotide sequences, predicted coding region nucleotide sequences, and translated amino acid sequences are provided in Additional files 1, 2, and 3, respectively.

Both the initial contigs (composed of unpaired reads) and the scaffolds contained a large number of short sequences. In total there were 147,010 initial contigs with an $\mathrm{N}_{50}$ of 493 and an $\mathrm{L}_{50}$ of $22,178 \mathrm{bp}$. This

Table 1 Pyrenophora teres f. teres genome assembly key parameters

\begin{tabular}{lc}
\hline Parameter & Value \\
\hline Size $(b p)$ & $41,957,260$ \\
G + C percentage & 48 \\
Predicted protein coding genes $\geq 100$ amino acids & 11,089 \\
Predicted protein coding sequences $\geq 50$ amino acids & 11,799 \\
$\quad$ Conserved proteins ${ }^{a}$ & 11,031 \\
$\quad$ Unique hypothetical proteins & 766 \\
$\quad$ Percent complete & 97.57 \\
Mean gene size (bp) & 1411 \\
Mean exon size (bp) & 557 \\
Mean number of exons per gene & 2.53 \\
\hline
\end{tabular}

${ }^{a}$ Significant at an e-value cutoff of $\leq 10^{-5}$. 
compared with a total of 146,737 scaffolds. The majority of initial contigs $(140,326$ of 147,010$)$ were $200 \mathrm{bp}$ or less, and were shared with the scaffold file. Such short contigs are a result of reads from repetitive regions. In AbySS, where highly similar repetitive regions occur, a 'bubble' removal algorithm simplifies the repeats to a single sequence. Thus, short isolated 'singletons' occur that were not assembled into scaffolds. Gene rich, more complex regions of the genome were represented by 6,684 scaffolds containing over $80 \%$ of the assembled sequences.

The assembly contains 11,799 predicted gene models of 50 amino acids or more. Most of the predicted genes (93.5\%) were conserved within other species and of these conserved genes, $45.2 \%$ showed very high homology with a BLASTP $e$-value of 0 . As a further confirmation of the success in capturing gene-rich regions, the percentage of complete genes (genes with defined start and stop codons) was $97.57 \%$.

To validate the assembly over relatively large distances, the assembly was compared to two Sanger sequenced BACs, designated 8F17 and 1H13. Direct BLASTN [18] against assembly scaffolds showed that complex or regions with a high GC content assembled effectively (Figure 1). BAC 1H13 contains several lowcomplexity regions containing repetitive sequences, in which Solexa reads were over-represented and where

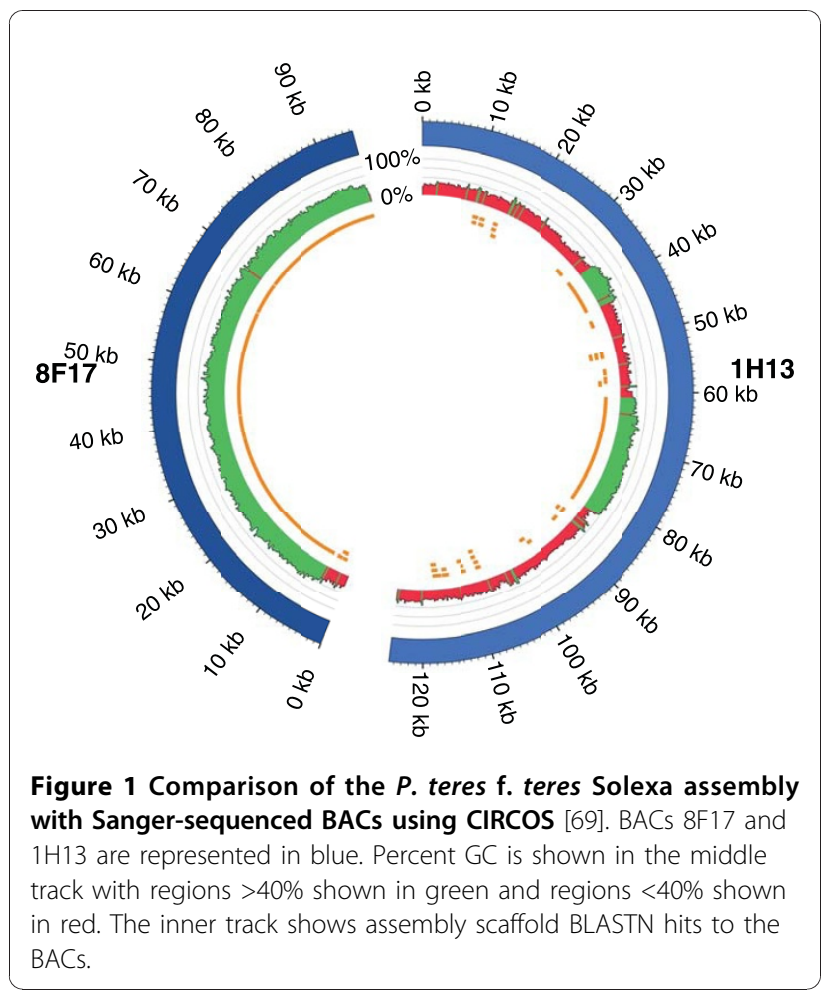

only short scaffold assemblies are evident (Additional file 4).

To validate the assembly over short distances of moderately low complexity, and to provide a resource for genetic mapping and genetic diversity studies, we created a set of simple sequence repeats (SSRs). Motif repeats ranged in size from $34 \mathrm{bp}$ with $100 \%$ identity and $0 \%$ indels to $255 \mathrm{bp}$ with $64 \%$ identity and $1 \%$ indels. We examined the amplification of a subset (75) of the primer pairs and all gave unambiguous single bands and robust amplification. Primer characteristics and amplicon sizes for the 75 SSRs are provided in Additional file 5 . The markers also readily amplified single bands in an isolate of $P$. teres $\mathrm{f}$. maculata, albeit with slightly lower efficiency in $20 \%$ of the reactions. As a demonstration of their utility, three markers that were polymorphic between $P$. teres $\mathrm{f}$. teres and f. maculata were used to fingerprint eight randomly selected isolates of each form (Table 2). Markers (ACA) $18-34213$ and $(\mathrm{CTG})_{19}-61882$ were highly polymorphic in $P$. teres $\mathrm{f}$. teres and f. maculata, respectively, with eight and five alleles. Form-specific diagnostic band sizes are evident

Table 2 Inter-form amplification of genome assemblyderived simple sequence repeat markers

\begin{tabular}{|c|c|c|c|}
\hline \multirow[b]{2}{*}{ Isolate } & \multicolumn{3}{|c|}{ Marker $^{a}$} \\
\hline & $\begin{array}{c}(A C A)_{18^{-}} \\
34213\end{array}$ & $\begin{array}{c}(C A T)_{13^{-}} \\
49416\end{array}$ & $\begin{array}{c}\text { (CTG) }_{19^{-}} \\
61882\end{array}$ \\
\hline \multicolumn{4}{|l|}{ P. teres f. teres } \\
\hline Cad 1-3 & 161 & 230 & 177 \\
\hline Cor 2 & 206 & 242 & 180 \\
\hline Cun 1-1 & 200 & 230 & 177 \\
\hline Cun 3-2 & 215 & 230 & 180 \\
\hline NB100 & 182 & 230 & 177 \\
\hline OBR & 197 & 242 & 180 \\
\hline Stir 9-2 & 185 & 228 & 177 \\
\hline Won 1-1 & 256 & 242 & 177 \\
\hline $\begin{array}{l}\text { Number of } \\
\text { alleles }\end{array}$ & 8 & 3 & 2 \\
\hline \multicolumn{4}{|c|}{ P. teres f. maculata } \\
\hline WAC10721 & 197 & 230 & 196 \\
\hline WAC10981 & 149 & 221 & 189 \\
\hline WAC11177 & 149 & 218 & 189 \\
\hline WAC11185 & 149 & 221 & 189 \\
\hline Cad 6-4 & 149 & 221 & 196 \\
\hline Mur 2 & 149 & 221 & 186 \\
\hline NFR & 149 & 221 & 199 \\
\hline SG1-1 & 149 & 221 & 190 \\
\hline $\begin{array}{l}\text { Number of } \\
\text { alleles }\end{array}$ & 2 & 3 & 5 \\
\hline
\end{tabular}

Examples of allele sizes from three SSRs are shown for eight randomly selected $P$. teres $f$. teres and $P$. teres $f$. maculata isolates. ${ }^{a}$ Includes SSR motif, template copy number in subscript, and numeric identifier. 
from the data, but with overlap in the ranges of allele sizes of each form for $(\mathrm{CAT})_{13^{-}} 49416$, and for (ACA) ${ }_{18^{-}}$ 34213 at $197 \mathrm{bp}$.

In addition to the above assembly validations, we compared 50 randomly selected non-homologous ESTs against the assembly to determine their presence; 49 gave unambiguous matches, with the highest $e$-value cutoff $<10^{-80}$, and one gave no hit. This orphan EST showed no BLASTX similarity to any sequence in GenBank and might be regarded as a library contaminant. Forty-seven (96\%) of the remaining ESTs were predicted by GeneMark.

\section{Electrophoretic and cytological karyotyping of $P$. teres $f$. teres}

To estimate the genome size of $P$. teres $\mathrm{f}$. teres by pulsed-field gel electrophoresis (PFG), isolate $0-1$ was examined and compared to isolate 15A. Isolate 0-1 showed at least seven chromosome bands as indicated in Figure 2, with estimated sizes of 6.0, 4.9, 4.7, 3.9, 3.6, 3.4, and $3 \mathrm{Mbp}$. The brightness of the band at $6.0 \mathrm{Mbp}$ indicated the presence of at least two chromosomes, and was further resolved into bands of 5.8 and $6.2 \mathrm{Mbp}$ on a second longer electrophoresis run (image not shown). The relative brightness of the $3.4 \mathrm{Mbp}$ band indicates two and possibly three chromosomes are comigrating. The smallest band visible in Figure 2 is less than $1 \mathrm{Mbp}$ and is most likely mitochondrial DNA.

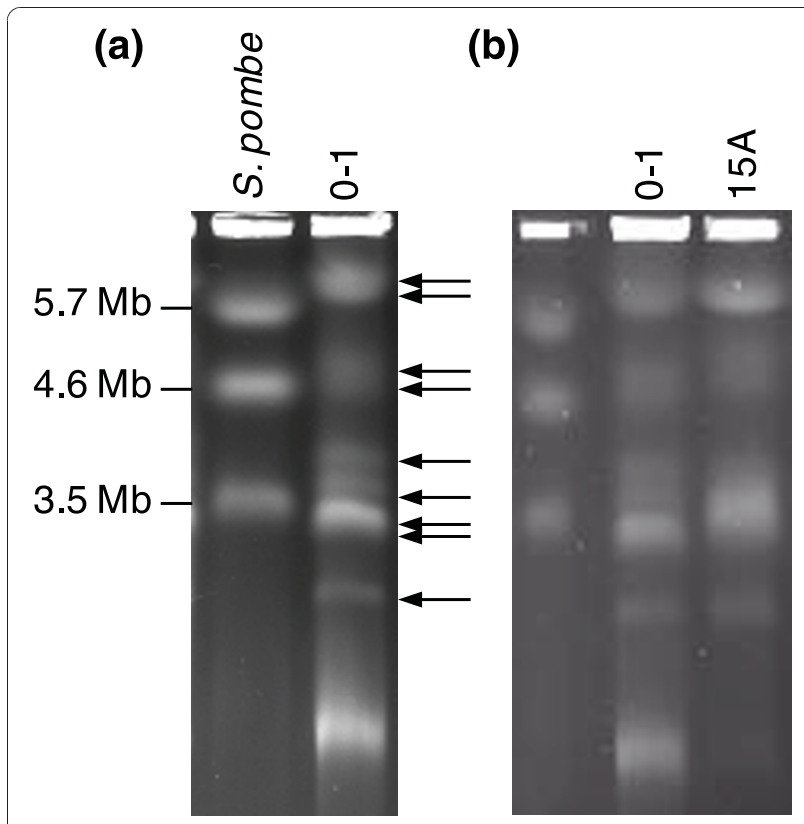

Figure 2 CHEF (clamped homogenous electric fields) separations of $\boldsymbol{P}$. teres $\mathbf{f}$. teres chromosomes. (a) Electro-

karyotypes of isolate 0-1 with nine chromosomal bands indicated. (b) Chromosome level polymorphisms between isolates 0-1 and $15 \mathrm{~A}$
Thus, there is a minimum of nine and as many as eleven chromosomes present in isolate $0-1$. This gave an estimated genome size of between 35.5 and $42.3 \mathrm{Mbp}$. Isolate 15A shows conspicuous differences in the lengths of the chromosomes for intermediate sized bands (greater than $3 \mathrm{Mbp}$ and less than $6 \mathrm{Mbp}$ ), and appears to have two bands around $3 \mathrm{Mbp}$.

Cytological karyotyping of isolate 0-1 using the germ tube burst method (GTBM) is depicted in Figure 3. Most of the discharged nuclei (above 90\%) were observed at interphase (Figure 3a) where the chromosomes exist in the form of chromatin and are enclosed by the nuclear membrane. Of the remaining $10 \%$, most of the chromosomes were either in early metaphase or clumped and entangled together, making it difficult to distinguish chromosomes (Figure 3b). In a few nuclei, condensed metaphase chromosomes were spread out sufficiently and we were able to count at least nine chromosomes (highlighted in Figure 3c). The four largest chromosomes are longer than or equal to $2 \mu \mathrm{m}$. The remainder depicted are smaller, but likely to be longer than $1 \mu \mathrm{m}$. The four largest chromosomes likely correspond to the four bands shown in PFG electrophoresis that have sizes greater than 3.9 Mbp.

\section{Gene content}

The genome assembly as a whole contains many predicted genes that have been implicated in pathogenicity. Genes encoding efflux pumps have roles in multidrug and fungicide resistance and toxic compound exclusion. For example, the ABC1 transporter in Magnaporthe grisea protects the fungus against azole fungicides and the

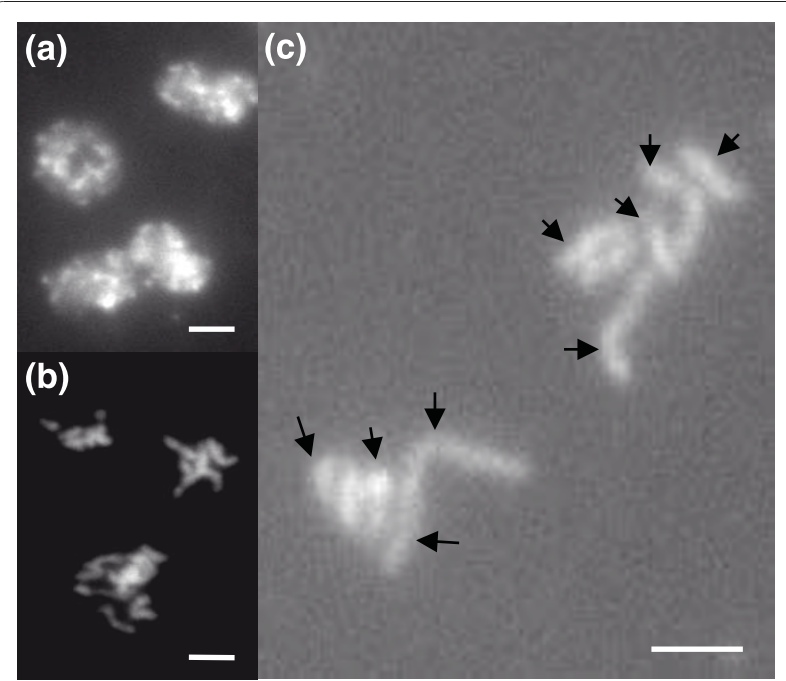

Figure 3 Visualization of $P$. teres $f$. teres chromosomes using the germ tube burst method (GTBM). (a) Nuclei at interphase. (b) Nuclei at early metaphase. (c) Condensed metaphase chromosomes with nine larger chromosomes indicated. Scale bars $=2 \mu \mathrm{m}$. 
rice phytoalexin sakuranetin [19]. These genes are especially prevalent, with 79 homologues including representatives of the ATP-binding cassette $(A B C)$, major facilitator, and multi antimicrobial extrusion protein superfamilies. Proteins encoded by other notable gene family members are the highly divergent cytochrome P450 s [20], which are involved in mono-oxidation reactions, one member of which has been shown to detoxify the antimicrobial pea compound pisatin [21]; the siderophores, which contribute to iron sequestration and resistance to oxidative and abiotic stresses but which also have essential roles in protection against antimicrobials and formation of infection structures [22,23]; and the tetraspanins, which are required for pathogenicity in several plant pathogenic fungi, one of which is homologous to the newly uncovered Tsp3 family [24].

\section{Genome-specific expansion of non-orthologous gene families}

Cluster analysis of $P$. teres $\mathrm{f}$. teres genes in OrthoMCL [25] against the closely related Dothideomycetes species for which genomes and/or ESTs have been made publicly available (Pyrenophora tritici-repentis, Cochliobolus heterostrophus, Stagonospora nodorum, Leptosphaeria maculans, Mycosphaerella graminicola, together with two Ascochyta spp. sequenced in-house, Ascochyta rabiei and Phoma medicaginis (Ramisah Mod Shah and Angela Williams, personal communication) was used to reveal $P$. teres $\mathrm{f}$. teres-specific expansion of gene families. The largest group of these were new members of class I and II transposable elements (Figure 4). Class I transposable elements are retrotransposons that use a RNA intermediate and reverse transcriptase to replicate, while class II transposons use a transposase to excise and reinsert a copy. In total, 36 clusters of new class I and II transposable elements are present in the assembly.

A prominent feature of expanded gene families in $P$. teres $\mathrm{f}$. teres is a substantial expansion in specialized multi-functional enzymes known as non-ribosomal peptide synthetases (NRPSs) and polyketide synthases (PKSs) that produce secondary metabolites. The nonorthologous NRPSs are present in 10 clusters of 22 genes. NRPSs catalyze the production of cyclic peptides to form a diverse range of products, including antibiotics and siderophores, and are known to be phytotoxic [26]. Among plant pathogenic Pleosporales fungi, HC toxin from Cochliobolus carbonum [27] and AM toxin from Alternaria alternata [28] are notable examples. Also evident are hybrid NRPS-PKSs [29] in two clusters of four genes. PKSs produce polyketides in a manner similar to fatty acid biosynthesis. In fungi, better known polyketides are the mycotoxins fumonisin and autofusarin, and the phytotoxin cercosporin [30]. Hybrid NRPS-PKSs occur where PKS and NRPS modules

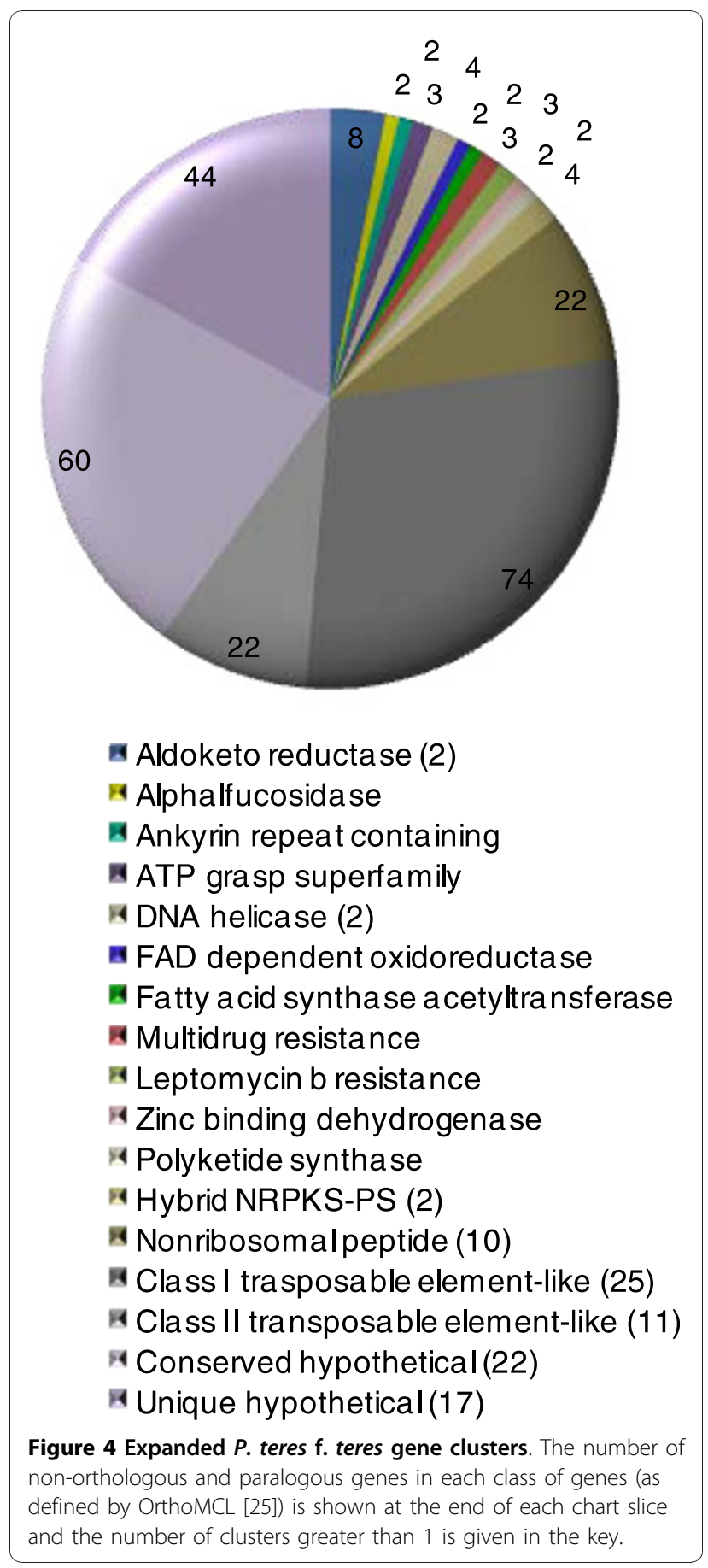

coexist and add to the complexity of secondary metabolites. Most of the remaining non-orthologous gene clusters include homologues to genes involved with secondary metabolism and signaling. Investigations into the functional significance of these genes may provide new insights into the requirements of this pathogen. Also present are six non-orthologous genes encoding antibiotic and multi-drug resistance proteins that may 
have a role against toxic plant compounds. Indeed, the $P$. teres f. teres assembly as a whole contains ten genes with homology to $\mathrm{ABC}$ drug transporters.

\section{Secreted proteins}

Comparisons between plant pathogenic ascomycetes $S$. nodorum and $M$. grisea with the saprophyte Neurospora crassa [31,32] have both shown the expansion of secreted gene families consistent with their roles as plant pathogens. $P$. teres $\mathrm{f}$. teres contains a large number of genes $(1,031)$ predicted to be secreted by both WolfPSORT [33] and SignalP [34]. A significant proportion of these genes in P. teres f. teres (85\%) are homologous with $P$. tritici repentis, as might be expected given their close phylogenetic relationship. This contrasts with 54\% of the predicted genes in S. nodorum for which no phylogenetically close relative was sequenced [32]. Of the remaining genes, a small number (1.6\%) show strongest homology to species outside the Pleosporales, while 6\% are unique to $P$. teres $\mathrm{f}$. teres isolate $0-1$ with no functional annotation. These genes may include genes that have been laterally transferred.

In Blast2GO [35,36], $61.6 \%$ of the predicted genes were annotated with Gene Ontology (GO) terms. GO annotations are limited to well characterized genes but they do provide a useful overview. A large proportion of predicted genes encode proteins associated with plant cell wall and cutin degradation, presumably to degrade plant tissue during necrotrophic growth. Most are protein and carbohydrate hydrolases, together with carbohydrate binding proteins that target various polysaccharides (Table 3). For example, there are nine and seven predicted gene products with homology to cellulose binding proteins and cellulases, respectively, and five and four predicted gene products with homology to cutin binding proteins and cutinases, respectively. Predicted proteins annotated with the GO term 'pathogenesis' include homologues of glycosyl hydrolases, cutinase precursors, surface antigens, and a monoxygenase related to maackiain detoxification protein from Nectria haematococca [37].

\section{Marker development and linkage map construction}

A total of 279 amplified fragment length polymorphisms (AFLPs) were generated that were polymorphic between the mapping population parents $15 \mathrm{~A}$ and $0-1$ using 96 primer combinations of $8 \mathrm{MseI}$ primers and $12 \mathrm{EcoRI}$ primers (Additional file 6). On average, each pair produced approximately three polymorphic AFLPs. We identified a total of 68 polymorphic SSRs for genetic mapping; 44 from the genome assembly sequence, 20 from sequence tagged microsatellite site (STMS) markers [38], and 4 from ESTs (Additional file 5). In addition to AFLPs and SSRs, five random amplified
Table 3 Common GO terms associated with genes predicted to be secreted

\begin{tabular}{lll}
\hline GO identifier & Description & Number of genes \\
\hline Biological process & & 42 \\
GO:0006508 & Proteolysis & 25 \\
GO:0055114 & Oxidation reduction & 23 \\
GO:0043581 & Mycelium development & 16 \\
GO:0051591 & Response to cAMP & 14 \\
GO:0045493 & Xylan catabolic process & 9 \\
GO:0009405 & Pathogenesis & 8 \\
GO:0034645 & Macromolecule biosynthesis & 7 \\
GO:0044248 & Cellular catabolic process & 7 \\
GO:0021700 & Developmental maturation & 7 \\
GO:0006139 & Nucleic acid metabolism & 7 \\
GO:0050794 & Regulation of cellular process & 7 \\
GO:0006629 & Lipid metabolic process & 6 \\
GO:0019222 & Metabolic regulation & 6 \\
GO:0016998 & Cell wall catabolic process & 6 \\
GO:0034641 & Nitrogen metabolism & 6 \\
GO:0030245 & Cellulose catabolic process & 6 \\
GO:0006032 & Chitin catabolic process & 6 \\
GO:0006979 & Response to oxidative stress & 6 \\
GO:0009847 & Spore germination & 5 \\
GO:0007154 & Cell communication & 5 \\
GO:0006464 & Protein modification process &
\end{tabular}

Molecular function

GO:0016787 Hydrolase activity 193

GO:0043167 Ion binding 84

GO:0016491 Oxidoreductase activity 73

GO:0048037 Cofactor binding 36

GO:0000166 Nucleotide binding 36

GO:0030246 Carbohydrate binding 26

GO:0046906 Tetrapyrrole binding 16

GO:0001871 Pattern binding 14

GO:0016740 Transferase activity 13

GO:0016829 Lyase activity 9

GO:0005515 Protein binding 6

GO:0016874 Ligase activity 6

GO:0016853 Isomerase activity 6

Terms are filtered for $\geq 5$ members; molecular function $\mathrm{GO}$ terms are limited to GO term level 3

polymorphic DNA markers associated with AvrHar [39] and the mating type locus were genotyped across 78 progeny from the $15 \mathrm{~A} \times 0-1$ cross. All markers were tested for segregation ratio distortion; 69 (19\%) were significantly different from the expected $1: 1$ ratio at $P=$ 0.05 , of which 32 were distorted at $P=0.01$.

The genetic map was initially constructed with a total of 354 markers composed of 279 AFLPs, 68 SSRs, 5 random amplified polymorphic DNA markers, and a single mating type locus marker. The markers were first assigned into groups using a minimum LOD (logarithm 
of the odds) threshold of 5.0 and a maximum $\theta=0.3$. We excluded 111 markers from the map because they had a LOD $<3$ by RIPPLE in MAPMAKER [40]. The final genetic map was composed of 243 markers in 25 linkage groups, with each linkage group having at least 3 markers. The map spans 2,477.7 cM in length, with an average marker density of approximately one marker per ten centiMorgans (Figures 5 and 6). Individual linkage groups ranged from $24.9 \mathrm{cM}$ (LG25) to $392.0 \mathrm{cM}$ (LG1), with 3 and 35 markers, respectively. Three of the linkage groups had a genetic distance greater than 200 cM and 10 linkage groups had genetic distances of less than $50 \mathrm{cM}$, leaving 12 medium-sized linkage groups ranging between 50 and $200 \mathrm{cM}$. Other than a $30-\mathrm{cM}$ gap on LG2.1, the markers are fairly evenly distributed on the linkage groups without obvious clustering. Linkage groups 2.1 and 2.2 are provisionally aligned together in Figure 5 as they may represent a single linkage group. This association is based on forming a single linkage group at LOD $=2$, and by comparative mapping of SSR scaffold sequences with the $P$. tritici-repentis assembly (data not shown). The mating type locus mapped to linkage group LG4, and except for six of the small linkage groups, each linkage group has at least one SSR marker, which may allow comparisons to closely related genome sequences.

\section{Discussion}

This is the first wholly Illumina-based assembly of an ascomycete genome and the third assembly to be reported for a necrotrophic plant pathogenic ascomycete $[31,32]$. As might be expected, the P. teres $f$. teres genome assembly demonstrates that the short paired-end reads can be used to effectively capture higher complexity gene-containing regions. The assembly was validated by comparison to BAC sequences, ESTs and by direct amplification of predicted sequences across SSRs. Based on the published assemblies for the phytopathogens $M$. grisea and S. nodorum [31,32], the number of predicted genes in $P$. teres $\mathrm{f}$. teres is similar $(11,089$ versus 11,109 and 10,762, for genes larger than 100 amino acids or $S$. nodorum version 2 gene models, respectively). Gene prediction algorithms, even when trained on ESTs from the species in question, are unlikely to correctly predict all coding regions in more complex genomes, and in some instances require further corroborating data from approaches such as proteomics and mass-spectrometry [41]. Thus, the true number of genes may be less dependent on the assembly per se and gene models may be further adjusted, concatenated or introduced.

The inevitable corollary of an assembly based on short paired-end reads is that low-complexity regions (containing low GC content, simple microsatellites and repetitive DNA) are under-represented. As a consequence, the assembly is composed of a large number of singleton contigs that are inappropriate for estimating the genomic proportions of such regions. To support the minimum estimate of the genome size based on the assembly, and to provide basic information on chromosome composition, we conducted PFG and GTBM karyotyping. From the PFG results, we concluded that $P$. teres f. teres most likely contains a minimum of 9 chromosomes but with band intensities suggesting 11 chromosomes is possible. This provided an estimated genome size of at least $35.5 \mathrm{Mbp}$ and an upper value of $42.3 \mathrm{Mbp}$. Clumping and co-migration of bands is a common phenomenon in PFG, as shown, for example, by Eusebio-Cope et al. [42]. Resolution of co-migrating bands requires techniques such as Southern blotting [43] and fluorescence in situ hybridization [44] for accurate discrimination. However, the cytological karyotyping correlated with the PFG results in depicting at least nine chromosomes. An upper estimate of nine chromosomes was postulated for P. teres by Aragona et al. [45], although that study did not identify which $P$. teres form was examined, and the technique used gave poor resolution of bands between 4.5 and $>6 \mathrm{Mbp}$. Overall, the total assembly size in this study correlates with the higher estimate by elecrophoretic karyotyping and indicates a genome of at least $42 \mathrm{Mbp}$. This is somewhat larger than the Pleosporales assemblies reported to date for Cochliobolus heterostrophus (34.9 Mbp; Joint Genome Institute), P. tritici-repentis (37.8 Mbp; NCBI) and S. nodorum (37.1 Mbp [32]).

An expansion in genome size compared to other Pleosporales might be explained by the presence in the assembly of new classes of transposable elements and large numbers of novel repeats (over 60, although these data are incomplete due to poor assembly of degraded regions and therefore have not been shown). These in turn may also explain the large PFG chromosomal level polymorphisms between the two isolates examined here and the relatively large genetic map. Chromosomal level polymorphisms are a feature of some ascomycetes [46]. Among plant pathogenic fungi, there is growing evidence that host-specificity genes and effectors are located in or next to transposon-rich regions [31,47]. This provides opportunities for horizontal acquisition, duplication and further diversification to generate new, species-specific genetic diversity or, where they are recognized as an avirulence gene, to be lost, a process that may also aid host range expansion. The contribution of transposons in P. teres f. teres pathogenicity has yet to be determined, although we have preliminary data showing that the avirulence gene AvrHar is associated with transposon repeats on the second largest chromosome. There is no evidence in $P$. teres $\mathrm{f}$. teres for small chromosomes <2 Mbp, as in N. haematococca and $A$. 


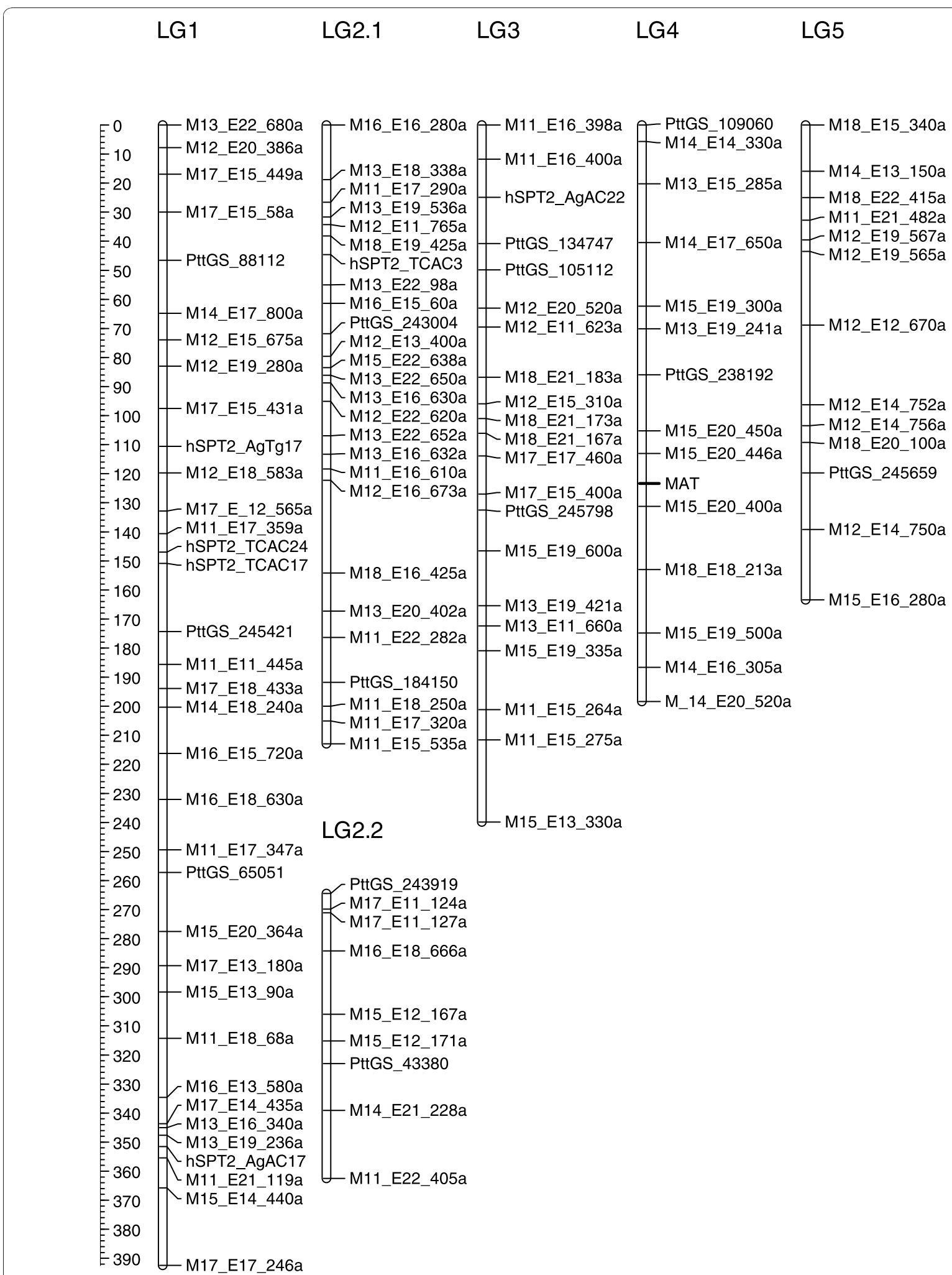

Figure 5 Genetic linkage map of $\boldsymbol{P}$. teres $\mathbf{f}$. teres. Linkage groups are drawn with genetic distance in $\mathrm{cM}$ on the scale bar to the left and are ordered according to their genetic length. AFLP markers are indicated by the Msel (M) and EcoRI (E) primer combination (Additional file 6), followed by the size of the marker. SSR markers were developed from three sources: ESTs, STMSs and the genome assembly, prefixed PtESTSSR_, hSPT2 2 , and PttGS, respectively. The mating type locus (MAT) is depicted in bold on linkage group 4. 


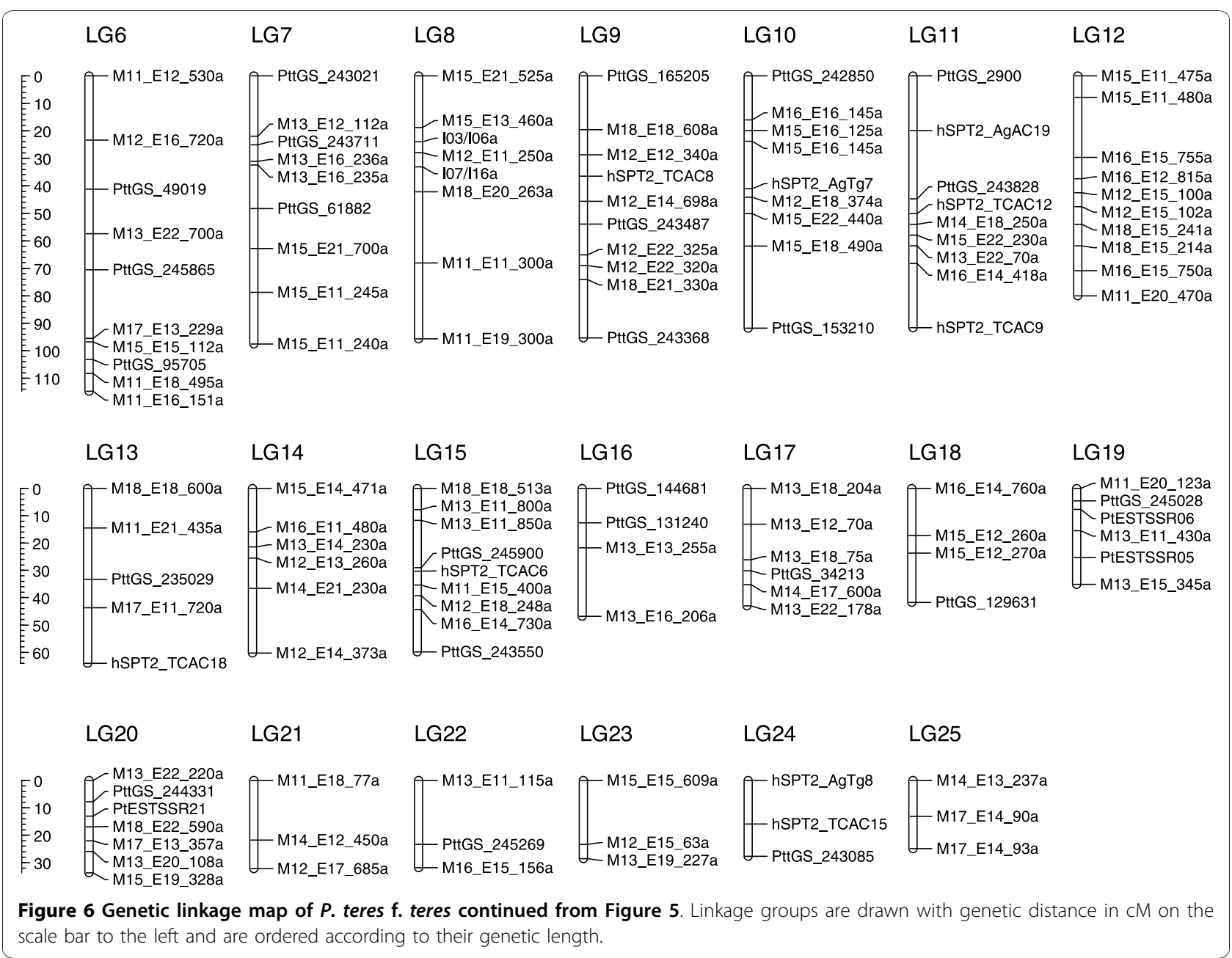

alternate, where they confer host-specific virulence $[48,49]$, and in Fusarium oxysporum, where they have been demonstrated to be mobile genetic elements conferring virulence to non-pathogenic strains [50].

The analysis of the gene content of the genome assembly shows that it shares many of the characteristics of similar plant pathogenic fungi, and strong homology to most genes from $P$. tritici-repentis. These include highly diverse proteins involved in host contact, signal transduction, secondary metabolite production and pathogenesis. Secreted proteins are of particular interest to plant pathologists since they represent the key interface of host-pathogen interactions, notably avirulence proteins and effectors. These are key components of inducing disease resistance and promoting disease, while expressed effector proteins offer tangible discriminating resistance assay tools in a variety of breeding programs. This is because fungal necrotrophic disease is the sum of the contribution of individual effectors $[51,52]$ and single, purified effectors give a qualitative response when infiltrated into leaves. However, effector genes often encode small, cysteine-rich proteins with little or no orthology to known genes. Examples include Avr2 and Avr4 in Cladosporium fulvum, Avr3 in F. oxysporum (reviewed in [53]), ToxA and ToxB in $P$. tritici repentis $[54,55]$ and SnToxA and SnTox3 in S. nodorum [56,57]. Identifying candidate effectors in the genome assembly in conjunction with genetic mapping, functional studies and proteomic approaches will in future aid their isolation.

We provide the first genetic linkage map of $P$. teres $\mathrm{f}$. teres. The total length is nearly $2,500 \mathrm{cM}$, longer than that reported for other ascomycete fungal pathogens; $1,216 \mathrm{cM}$ for M. graminicola [58], 1,329 cM for Cochliobus sativus [59], and $900 \mathrm{cM}$ for M. grisea [60]. However, a genetic map of 359 loci for the powdery mildew fungus Blumeria graminis f. sp. hordei, an obligate biotrophic pathogen of barley, covered 2,114 cM [61]. The length of the genetic map of $P$. teres $f$. teres may be a function of the relatively large genome size and the presence of large numbers of recombinogenic repetitive elements. This is paralleled by a greater number of linkage 
groups (25) compared to the estimated number of chromosomes that may also be suggestive of interspersed tracts of repetitive DNA.

The genetic map and karyotyping data will be instrumental in a final assembly of the P. teres f. teres genome, as they will allow scaffolds to be orientated and tiled onto linkage groups. A combination of the genome assembly and the genetic map provides an invaluable resource to identify potential effector candidate genes from phytotoxic protein fractions in conjunction with mass spectrometry peptide analysis. Genetically characterized SSRs provided in this study will also provide an important resource for the community in comparative mapping, gene-flow and genetic diversity studies. Further validation, assembly of low-complexity sequence regions, and genome annotation are now underway using proteomic approaches and 454 pyrosequencing. The priority now is to fully understand the mechanism of pathogenicity in P. teres f. teres in order to achieve a solution to control this pathogen.

\section{Conclusions}

This study demonstrates that the successful assembly of more complex and gene-rich regions of a filamentous fungus is possible using paired-end Solexa sequencing. The approach provides a cost-effective means of directly generating marker resources that would previously have been prohibitively expensive with modest research funding. At $42 \mathrm{Mbp}$ or more, the genome of $P$. teres $\mathrm{f}$. teres $0-1$ is larger by comparison to closely related Pleosporales members, and has a correspondingly large genetic map. The genome is dynamic, in that different isolates show obvious chromosomal level differences, while fractionated linkage groups and the length of the genetic map also suggest an abundance of repetitive DNA. In common with other plant pathogens, $P$. teres f. teres contains a rich diversity of predicted genes, notably protein and carbohydrate hydrolases, efflux pumps, cytochrome P450 genes, siderophores, tetraspanins, nonribosomal peptide synthetases and polyketide synthases, and a complex secretome that can be attributed to its lifestyle. Non-ribosomal peptide synthetases and efflux pumps in particular appear to have undergone a $P$. teres f. teres-specific expansion of non-othologous gene families. The assembly presented provides researchers with an excellent resource to further examine net blotch pathogenicity and plant-microbe interactions in general.

\section{Materials and methods}

\section{Origin of $P$. teres isolates}

The NFNB isolate sequenced in this study, 0-1, was originally collected in Ontario, Canada [39]. Isolate 15A (10-15-19), the opposite parental isolate used to develop a mapping population, was collected from Solano
County, California [62]. The remaining NFNB isolates (Cad 1-3, Cor 2, Cun 1-1, Cun 3-2, NB100, OBR, Stir 92, and Won 1-1) were collected in Western Australia by S Ellwood in the 2009 barley growing season. SFNB isolates WAC10721, WAC10981, WAC11177, and WAC11185 were obtained from the Department of Agriculture and Food, Western Australia (3, Baron Hay Court, South Perth, Western Australia 6151); isolates Cad 6-4, Mur 2, NFR, and SG1-1 were collected in Western Australia by S Ellwood during 2009.

\section{Electrophoretic and cytological karyotyping Protoplasting and pulsed-field gel electrophoresis}

Chromosome size and number were analyzed for North American NFNB isolates; 0-1 and 15A, previously used to develop a genetic cross for identifying avirulence genes $[39,63]$. Fungal protoplasts were prepared using a protocol established for $S$. nodorum as described by Liu et al. [56] with some modifications. Briefly, conidia were harvested from 7-day fungal cultures and inoculated into $60 \mathrm{ml}$ liquid Fries medium in $250 \mathrm{ml}$ Erlenmeyer flasks. After growth at $27^{\circ} \mathrm{C}$ in a shaker $(100 \mathrm{rpm})$ for $48 \mathrm{~h}$, the fungal tissue was then homogenized in a Waring blender and re-inoculated into $200 \mathrm{ml}$ liquid Fries medium in $500 \mathrm{ml}$ Erlenmeyer flasks. The fungus was grown under the same growth conditions for $24 \mathrm{~h}$. Mycelium was harvested by filtering through two layers of Miracloth, washed thoroughly with water and finally with mycelial wash solution (MWS: $0.7 \mathrm{M} \mathrm{KCl}$ and 10 $\mathrm{mM} \mathrm{CaCl} 2$ ). Around $2 \mathrm{~g}$ (wet weight) of mycelial tissue was then transferred into a Petri dish $(100 \times 20 \mathrm{~mm})$ containing $40 \mathrm{ml}$ filter-sterilized protoplasting solution containing $40 \mathrm{mg} / \mathrm{ml} \beta$-d-glucanase, $0.8 \mathrm{mg} / \mathrm{ml}$ chitinase, and $5 \mathrm{mg} / \mathrm{ml}$ driselase (Interspex Product Inc., San Mateo, CA, USA) in MWS. The Petri dish was shaken at $70 \mathrm{rpm}$ at $28^{\circ} \mathrm{C}$ for at least $5 \mathrm{~h}$. Protoplasts were filtered through four layers of Miracloth and pelleted by centrifugation at 2,000 $\times g$ for 5 minutes at room temperature, followed by another wash with MWS and pelleting. Protoplasts were resuspended in MWS to a final concentration of $2 \times 10^{8}$ protoplasts $/ \mathrm{ml}$ and mixed with an equal volume of $2 \%$ low melting temperature agarose (Bio-Rad Laboratories, Hercules, CA, USA) dissolved in MWS. Agarose plugs were made by pipetting $80 \mu \mathrm{l}$ of the mixture into plug molds (Bio-Rad Laboratories). Once solidified, plugs were placed in $20 \mathrm{ml}$ Proteinase $\mathrm{K}$ reaction buffer containing $100 \mathrm{mM}$ EDTA (pH 8.0), 1\% $\mathrm{N}$-lauroyl sarcosine, $0.2 \%$ sodium deoxycholate and 1 $\mathrm{mg} / \mathrm{ml}$ Proteinase K (USBiological, Swampscott, MA, USA) at $50^{\circ} \mathrm{C}$ for $24 \mathrm{~h}$. Plugs were washed four times in $10 \mathrm{mM}$ Tris $\mathrm{pH} 8.0$ and $50 \mathrm{mM}$ EDTA for $1 \mathrm{~h}$ with gentle agitation, then stored in 0.5 M EDTA ( $\mathrm{pH}$ 8.0) at $4^{\circ} \mathrm{C}$. PFG was performed on a Bio-Rad CHEF Mapper system. Separation of chromosomes in the 1 to $6 \mathrm{Mb}$ 
range was carried out in $1.0 \times \mathrm{TAE}$ at $14^{\circ} \mathrm{C}$ using $0.8 \%$ Low EEO agarose gel (USBiological). Run time was $72 \mathrm{~h}$ at $2 \mathrm{~V} / \mathrm{cm}(70 \mathrm{~V})$ with a 20 - to 40 -minute switch time ramp at an angle of $106^{\circ}$.

\section{Spore germination and germ tube burst cytological karyotyping}

Conidia were washed with water from 7-day cultures grown on V8 potato dextrose agar (V8PDA) plates, filtered through two layers of miracloth and centrifuged at $3,000 \times g$ for 5 minutes. Conidia were washed twice with potato dextrose broth and re-suspended in this with a final concentration of $4 \times 10^{5}$ spores $/ \mathrm{ml}$. Approximately $400 \mu \mathrm{l}$ of spore suspension was placed onto slides coated with poly-L-lysine (Sigma-Aldrich Corp., St Louis, MO, USA) and covered by a $22 \times 40$ $\mathrm{mm}$ piece of parafilm to keep moist. All slides were kept in a sealed plastic box at room temperature for 3 $\mathrm{h}$, and then moved to the fridge for cold treatment overnight. Slides were dipped in $\mathrm{H}_{2} \mathrm{O}$ to carefully remove the covers and then placed in a methanol/acetic acid (22:3) solution overnight to fix fungal tissue. The slides were flame dried to burst cells and release chromosomes. Slides were stained for 5 minutes in the dark with $1 \mu \mathrm{g} / \mathrm{ml}$ 4',6-diamidino-2-phenylindole (DAPI; Sigma-Aldrich) and $1 \mu \mathrm{g} / \mathrm{ml}$ Flourescent Brightener 28 (Sigma-Aldrich) in anti-fade mounting solution. Slides were examined and photographed using a Zeiss Axioplan 2 epiflourescent microscope.

\section{Genome sequence acquisition}

\section{Whole shotgun genome sequencing}

DNA of P. teres $\mathrm{f}$. teres isolate 0-1 was extracted using a Biosprint DNA Plant Kit and a BioSprint 15 automated workstation (Qiagen, Hilden, Germany). Genomic sequencing was performed on a Solexa sequencing platform at the Allan Wilson Centre (Massey University, Palmerston North, New Zealand). DNA preparation, cluster formation, primer hybridization and DNA amplification reactions were according to the manufacturer's recommended protocol [64]. DNA sequencing was performed using 75-bp paired-end reads of randomly sheared 200-bp fragments in a single flow cell. Data were pre-filtered in Illumina's Pipeline v.1.4 and IPAR v.1.3. Reads failing a 'chastity' filter of 0.6 were discarded. The steps described below for genome scaffold assembly, annotation and analysis were performed on the iVEC advanced computing facilities [65].

\section{Paired-end scaffold assemblies}

Single (split pairs) and paired-end reads were assembled using ABySS v.1.0.14 [17]. In addition to the read filtering described above, ABySS removes reads containing ambiguous characters (Ns). The optimal sequence kmer (overlap) length was determined by incrementally adjusting the kmer length by $4 \mathrm{bp}$ and graphing the number of contigs against $\mathrm{L}_{50}$ for a given kmer length. The optimal kmer length occurred where $\mathrm{N}_{50}$ was minimal and $L_{50}$ was largest as visualized by $R$ [66]. $N_{50}$ is a weighted median statistic such that $50 \%$ of the entire assembly is contained in the number of contigs or scaffolds equal to or greater than this value, while $L_{50}$ is the length of the scaffold that separates the half of the assembled genome from the remainder of smaller scaffolds, if the sequences are ordered by size.

\section{Annotation and analysis}

Protein coding sequences were identified with GeneMarkES v.2 [67]. GeneMark uses a self-training algorithm optimized for features of fungal gene organization by incorporating an enhanced intron submodel to accommodate sequences with and without branch point sites. GeneMark compares favorably with the accuracy of gene finders that employ supervised training based on cDNA sequences.

Annotation of predicted proteins was conducted with the following tools. A mirror of the NCBI database at iVEC, together with publicly available fungal protein sequence files not present at NCBI, was interrogated by BLASTP [18]. Blast2GO v.2.4.2 [35,36], which incorporates GO, KEGG maps, InterPro and Enzyme Codes was used with default parameters for functional annotation. De novo annotation of PFAM domains was performed using HMMER v.2.3.2 [68]. HMMER searches for homologues of protein sequences and implements methods using probabilistic models called 'profile hidden Markov models'. To detect orthologous genes, we used OrthoMCL [25] by BLAST to the NCBI non-redundant database with an $e$-value cutoff of $\leq 10^{-5}$. OrthoMCL is a genome-scale algorithm for grouping protein sequences between species based on BLAST similarity that was used to identify species-specific expanded gene families. Subcellular localization of proteins and secretion signals were identified with Wolf PSort [33] and SignalP v.3.0 [34] using default parameters and selection of the appropriate organism type.

\section{Genome assembly validation}

\section{Assembly comparison with Sanger-sequenced BACs}

To validate the assembly over a larger scale, BLASTN [18] was used to compare the assembly against two NFNB 0-1 BACs, designated 8F17 and 1H13, sequenced and assembled by The Genome Center (Washington University, St Louis, MO, USA). The data were visualized with CIRCOS [69]. To establish if all regions of the BACs were covered by Solexa sequencing, raw reads were mapped to the BACs with the Burrows-Wheeler Aligner [70] and visualized using $\mathrm{R}$ and the ggplot2 package [66,71].

\section{SSR primer design and PCR amplification}

Short tandem repeats or SSRs (also known as microsatellites) were identified by scanning the genome 
assembly with Tandem Repeat Finder v.4 [72] for a minimum of ten tandem repeats from 2 to $7 \mathrm{bp}$. Primers were designed using Primer3 [73] using parameters designed to minimize secondary structures, with a GC content $>40 \%$, and an optimum melting temperature of 58 to $60^{\circ} \mathrm{C}$, for amplicons in a size range of 150 to $400 \mathrm{bp}$. The primers were assayed using single-spored $P$. teres isolates collected from different sites in Western Australia. DNA extraction and PCR amplification using the Multiplex Ready Technique were performed as described previously $[74,75]$. Allele sizing was performed using GeneMapper v.3.7 (Applied Biosystems, Foster City, CA, USA).

\section{EST library preparation, sequencing, and assembly comparison}

Total RNA was extracted from isolate $0-1$ using fungal mycelium tissue grown in liquid Fries medium for 4 days. The RNA was extracted with TRIZOL (Invitrogen, Carlsbad, CA, USA) following the manufacturer's instructions. EST library construction and sequencing was conducted by The Genome Center. To investigate the presence of ESTs in the assembly and the efficiency of GeneMark predictions, unique EST sequences were BLASTN searched against the assembly. BLASTN hits were then compared against the location of GeneMark predicted coding regions with BEDtools [76].

\section{Marker development and genetic linkage map construction}

Lai et al. [63] used a subset of AFLPs to identify markers associated with fungal avirulence on the barley lines 'Harbin' and 'Prato' on two linkage groups. That study used a segregating population of 78 progeny from a cross between NFNB isolates 15A and 0-1. The AFLP markers were generated based on the technique of Vos et al. [77] and employed 96 primer combinations containing EcoRI and MseI restriction sites. In this study, all available AFLPs from the 96 primer combinations were used to develop a comprehensive genetic map (Additional file 6). In addition, we incorporated polymorphic STMSs developed from microsatellite libraries by Keiper et al. [38], together with SSRs from EST sequences and the genome assembly herein. SSR PCR amplification and population genotyping were performed as described previously $[38,78,79]$. In addition, the mating type locus was assayed using primers Pt5 and Pt7 that amplify the P. teres HMG box [80].

Linkage map construction was performed with MAPMAKER v.2.0 for Macintosh as described by Liu et al. [78]. A minimum LOD value of 5.0 and a maximum $\theta=$ 0.3 were used to establish the linkage groups. For each linkage group, the most plausible order of markers was determined using commands 'FIRST ORDER' and 'RIPPLE', and markers with low confidence (LOD $<3.0$ for RIPPLE) were excluded from the map. All markers were tested for fitness of a 1:1 segregation ratio using Qgene
[81]. The genetic map was drawn with the software program MapChart v.2.1 [82].

\section{Additional material}

\section{Additional file 1: $P$. teres $\mathrm{f}$. teres isolate $0-1$ scaffold assembly} nucleotide sequences.

Additional file 2: $P$. teres $\mathrm{f}$. teres isolate $\mathbf{0 - 1}$ predicted coding region nucleotide sequences.

Additional file 3: $P$. teres $\mathrm{f}$. teres isolate $0-1$ predicted coding region translated amino acid sequences.

Additional file 4: Solexa read coverage of BACs $1 \mathrm{H} 13$ and 8F17.

Additional file 5: Characteristics of 75 genome assembly-derived SSRs and those polymorphic SSRs used in the $P$. teres f. teres $01 \times$ 15A genetic map construction.

Additional file 6: AFLP di-nucleotide selective primer extensions and their codes.

\section{Abbreviations}

ABC, ATP-binding cassette; AFLP, amplified fragment length polymorphism; BAC, bacterial artificial chromosome; bp, base pair; DDBJ, DNA Data Bank of Japan; EST, expressed sequence tag; GO, Gene Ontology; GTBM, germ tube burst method; LOD, logarithm of the odds; MWS, mycelial wash solution; NCBI, National Center for Biotechnology Information; NFNB, net form of net blotch; NRPS, non-ribosomal peptide synthetase; PFG, pulsed-field gel electrophoresis; PKS, polyketide synthase; SFNB, spot form of net blotch; SSR, simple sequence repeat; STMS, sequence-tagged microsatellite site.

\section{Acknowledgements}

The authors would like to thank Dr Steven Xu and Dr CC Jan for their assistance in chromosomal microscopy. This research was funded by the Grains Research and Development Corporation under project UMU00025.

\section{Author details}

${ }^{1}$ Department of Environment and Agriculture, Curtin University, Kent Street, Bentley, Perth, Western Australia 6102, Australia. ${ }^{2}$ Department of Plant Pathology, North Dakota State University, Fargo, North Dakota 58105, USA. ${ }^{3}$ CSIRO Plant Industry, Centre for Environment and Life Sciences, Private Bag 5, Wembley, Western Australia 6913, Australia. ${ }^{4}$ South Australian Research and Development Institute, Waite Institute, Adelaide, South Australia 5064, Australia. ${ }^{5}$ Division of Health Sciences, Murdoch University, Murdoch Drive, Perth, Western Australia 6150, Australia. ${ }^{6}$ USDA-ARS Cereal Crops Research Unit, Northern Crop Science Laboratory, 1307 18th Street North, Fargo, North Dakota 58105, USA.

\section{Authors' contributions}

SRE analyzed the data, wrote the manuscript, and performed initial laboratory SSR genetic marker validation. RAS provided informatics expertise in software implementation, scripting and primary data analysis (including for genome assembly, gene prediction, annotation of predicted peptides, and homology searches). JKH provided scripts to facilitate SSR design and data elucidation. CSM assisted with comparisons of predicted Pyrenophora proteins. ZL screened for polymorphic SSR markers on genetic mapping population parents and conducted genotyping, genetic map construction, and electrophoretic karyotyping. FK contributed STMS markers. ZL undertook the AFLP genotyping and the cytological karyotyping. RPO and TLF contributed to the design of the project and provided assistance in finalizing the manuscript prior to publication.

Received: 25 June 2010 Revised: 21 October 2010

Accepted: 10 November 2010 Published: 10 November 2010

\section{References}

1. Mathre DE: Compendium of Barley Diseases. 2 edition. St Paul MN, American Phytopathological Society; 1997. 
2. Murray GM, Brennan JP: Estimating disease losses to the Australian barley industry. Aust Plant Pathol 2010, 39:85-96.

3. Smedegård-Petersen V: Pyrenophora teres f. maculata f. nov. and Pyrenophora teres f. teres on barley in Denmark. Kgl Vet Landbohojsk Arsskr $1971,124-144$

4. Rau D, Attene G, Brown A, Nanni L, Maier F, Balmas V, Saba E, Schäfer W, Papa R: Phylogeny and evolution of mating-type genes from Pyrenophora teres, the causal agent of barley 'net blotch' disease. Curr Genet 2007, 51:377-392.

5. Campbell GF, Lucas JA, Crous PW: Evidence of recombination between net- and spot-type populations of Pyrenophora teres as determined by RAPD analysis. Mycol Res 2002, 106:602-608.

6. Leisova L, Kucera L, Minarikova V, Ovesna J: AFLP-based PCR markers that differentiate spot and net forms of Pyrenophora teres. Plant Pathol 2005, 54:66-73.

7. McLean MS, Howlett BJ, Hollaway GJ: Spot form of net blotch, caused by Pyrenophora teres f. maculata, is the most prevalent foliar disease of barley in Victoria, Australia. Aust Plant Pathol 2010, 39:46-49.

8. Tekauz A: Characterisation and distribution of pathogenic variation in Pyrenophora teres f. teres and $P$. teres f. maculata from western Canada. Can J Plant Pathol 1990, 12:141-148.

9. Sarpeleh A, Tate ME, Wallwork H, Catcheside D, Able AJ: Characterisation of low molecular weight phytotoxins isolated from Pyrenophora teres. Physiol Mol Plant Pathol 2009, 73:154-162.

10. Sarpeleh A, Wallwork H, Catcheside DE, Tate ME, Able AJ: Proteinaceous metabolites from Pyrenophora teres contribute to symptom development of barley net blotch. Phytopathology 2007, 97:907-915.

11. Sarpeleh A, Wallwork H, Tate ME, Catcheside DE, Able AJ: Initial characterisation of phytotoxic proteins isolated from Pyrenophora teres. Physiol Mol Plant Pathol 2008, 72:73-79.

12. Flor HH: Current status of the gene-for-gene concept. Annu Rev Phytopathol 1971, 9:275-296.

13. McLean MS, Howlett BJ, Hollaway GJ: Epidemiology and control of spot form of net blotch (Pyrenophora teres f. maculata) of barley: a review. Crop Pasture Sci 2009, 60:303-315.

14. Liu Z, Ellwood SR, Oliver RP, Friesen TL: Pyrenophora teres: profile of an increasingly damaging barley pathogen. Mol Plant Pathol 2010.

15. Properties of Eukaryotic Genome Sequencing Projects. [http://www.ncbi. nlm.nih.gov/genomes/leuks.cgi].

16. Nowrousian M, Stajich JE, Chu M, Engh I, Espagne E, Halliday K, Kamerewerd J, Kempken F, Knab B, Kuo H-C, Osiewacz HD, Poggeler S, Read ND, Seiler S, Smith KM, Zickler D, Kuck U, Freitag M: De novo assembly of a $40 \mathrm{Mb}$ eukaryotic genome from short sequence reads: Sordaria macrospora, a model organism for fungal morphogenesis. PLOS Genet 2010, 6:e1000891.

17. Simpson JT, Wong K, Jackman SD, Schein JE, Jones SJM, Birol A: ABySS: A parallel assembler for short read sequence data. Genome Res 2009, 19:1117-1123.

18. Altschul S, Madden T, Schaffer A, Zhang J, Zhang Z, Miller W, Lipman D: Gapped BLAST and PSI-BLAST: a new generation of protein database search programs. Nucleic Acids Res 1997, 25:3389-3402.

19. Del Sorbo G, Schoonbeek H-j, De Waard MA: Fungal transporters involved in efflux of natural toxic compounds and fungicides. Fungal Genet Biol 2000, 30:1-15.

20. Deng J, Carbone I, Dean R: The evolutionary history of Cytochrome P450 genes in four filamentous Ascomycetes. BMC Evol Biol 2007, 7:30.

21. Maloney AP, VanEtten HD: A gene from the fungal plant pathogen Nectria haematococca that encodes the phytoalexin-detoxifying enzyme pisatin demethylase defines a new cytochrome P450 family. Mol Gen Genet 1994, 243:506-514.

22. Idnurm A, Howlett BJ: Pathogenicity genes of phytopathogenic fungi. $\mathrm{Mol}$ Plant Pathol 2001, 2:241-255.

23. Hof $\mathrm{C}$, Eisfeld $\mathrm{K}$, Welzel $\mathrm{K}$, Antelo L, Foster AJ, Anke H: Ferricrocin synthesis in Magnaporthe grisea and its role in pathogenicity in rice. Mol Plant Pathol 2007, 8:163-172.

24. Lambou K, Tharreau D, Kohler A, Sirven C, Marguerettaz M, Barbisan C, Sexton A, Kellner E, Martin F, Howlett B, Orbach M, Lebrun M-H: Fung have three tetraspanin families with distinct functions. BMC Genomics 2008, 9:63.
25. Chen F, Mackey AJ, Stoeckert CJ Jr, Roos DS: OrthoMCL-DB: querying a comprehensive multi-species collection of ortholog groups. Nucleic Acids Res 2006, 34:D363-368.

26. Walton JD: Host-selective toxins: agents of compatibility. Plant Cell 1996, 8:1723-1733.

27. Walton JD: HC-toxin. Phytochemistry 2006, 67:1406-1413.

28. Johnson RD, Johnson L, Itoh Y, Kodama M, Otani H, Kohmoto K: Cloning and characterization of a cyclic peptide synthetase gene from Alternaria alternata apple pathotype whose product is involved in AM-toxin synthesis and pathogenicity. Mol Plant Microbe Interact 2000, 13:742-753.

29. Silakowski B, Kunze B, Müller R: Multiple hybrid polyketide synthase/nonribosomal peptide synthetase gene clusters in the myxobacterium Stigmatella aurantiaca. Gene 2001, 275:233-240.

30. Daub ME, Ehrenshaft M: The photoactivated Cercospora toxin cercosporin: contributions to plant disease and fundamental biology. Annu Rev Phytopathol 2000, 38:461-490

31. Dean RA, Talbot NJ, Ebbole DJ, Farman ML, Mitchell TK, Orbach MJ, Thon M, Kulkarni R, Xu J-R, Pan H, Read ND, Lee Y-H, Carbone I, Brown D, Oh YY, Donofrio N, Jeong JS, Soanes DM, Djonovic S, Kolomiets E, Rehmeyer C, Li W, Harding M, Kim S, Lebrun M-H, Bohnert H, Coughlan S, Butler J, Calvo S, Ma L-J, et al: The genome sequence of the rice blast fungus Magnaporthe grisea. Nature 2005, 434:980-986.

32. Hane JK, Lowe RGT, Solomon PS, Tan K-C, Schoch CL, Spatafora JW, Crous PW, Kodira C, Birren BW, Galagan JE, Torriani SFF, McDonald BA, Oliver RP: Dothideomycete plant interactions illuminated by genome sequencing and EST analysis of the wheat pathogen Stagonospora nodorum. Plant Cell 2007, 19:3347-3368.

33. Horton P, Park K-J, Obayashi T, Nakai K: Protein subcellular localization prediction with WoLF PSORT. In Proceedings of the 4th Annual Asia-Pacific Bioinformatics Conference APBC06: 13-16 Feb 2006; Taipei, Taiwan Edited by: Jiang T, Yang U-C, Chen Y-PP, Wong L 2006, 39-48,

34. Emanuelsson $\mathrm{O}$, Brunak $\mathrm{S}$, von Heijne $\mathrm{G}$, Nielsen H: Locating proteins in the cell using TargetP, SignalP and related tools. Nat Protoc 2007, 2:953-971.

35. Conesa A, Gotz S, Garcia-Gomez JM, Terol J, Talon M, Robles M: Blast2GO: a universal tool for annotation, visualization and analysis in functional genomics research. Bioinformatics 2005, 21:3674-3676.

36. Gotz S, Garcia-Gomez JM, Terol J, Williams TD, Nagaraj SH, Nueda MJ, Robles M, Talon M, Dopazo J, Conesa A: High-throughput functional annotation and data mining with the Blast2GO suite. Nucleic Acids Res 2008, 36:3420-3435.

37. Covert S, Enkerli J, Miao V, VanEtten H: A gene for maackiain detoxification from a dispensable chromosome of Nectria haematococca. Mol Gen Genet 1996, 251:397-406.

38. Keiper FJ, Grcic M, Capio E, Wallwork H: Diagnostic microsatellite markers for the barley net blotch pathogens, Pyrenophora teres f. maculata and Pyrenophora teres f. teres. Aust Plant Pathol 2008, 37:428-430.

39. Weiland JJ, Steffenson BJ, Cartwright RD, Webster RK: Identification of molecular genetic markers in Pyrenophora teres f. teres associated with low virulence on 'Harbin' barley. Phytopathology 1999, 89:176-181.

40. Lander ES, Green P, Abrahamson J, Barlow A, Daly MJ, Lincoln SE, Newburg L: MAPMAKER: An interactive computer package for constructing primary genetic linkage maps of experimental and natural populations. Genomics 1987, 1:174-181.

41. Bringans S, Hane J, Casey T, Tan K-C, Lipscombe R, Solomon P, Oliver R: Deep proteogenomics; high throughput gene validation by multidimensional liquid chromatography and mass spectrometry of proteins from the fungal wheat pathogen Stagonospora nodorum. BMC Bioinformatics 2009, 10:301

42. Eusebio-Cope A, Suzuki N, Sadeghi-Garmaroodi H, Taga M: Cytological and electrophoretic karyotyping of the chestnut blight fungus Cryphonectria parasitica. Fungal Genet Biol 2009, 46:342-351.

43. Talbot NJ, Salch YP, Ma M, Hamer JE: Karyotypic variation within clonal lineages of the rice blast fungus, Magnaporthe grisea. Appl Environ Microbiol 1993, 59:585-593.

44. Taga M, Murata M, VanEtten HD: Visualization of a conditionally dispensable chromosome in the filamentous Ascomycete Nectria haematococca by fluorescence in situ hybridization. Fungal Genet Biol 1999, 26:169-177. 
45. Aragona M, Montigiani M, Porta-Puglia A: Electrophoretic karyotypes of the phytopathogenic Pyrenophora graminea and P. teres. Mycol Res 2000, 104:853-857.

46. Mehrabi R, Taga M, Kema GHJ: Electrophoretic and cytological karyotyping of the foliar wheat pathogen Mycosphaerella graminicola reveals many chromosomes with a large size range. Mycologia 2007, 99:868-876.

47. Friesen TL, Stukenbrock EH, Liu Z, Meinhardt S, Ling H, Faris JD, Rasmussen JB, Solomon PS, McDonald BA, Oliver RP: Emergence of a new disease as a result of interspecific virulence gene transfer. Nat Genet 2006, 38:953-956.

48. Miao V, Covert S, VanEtten $\mathrm{H}$ : A fungal gene for antibiotic resistance on a dispensable ("B") chromosome. Science 1991, 254:1773-1776.

49. Harimoto $Y$, Hatta $R$, Kodama M, Yamamoto M, Otani H, Tsuge T: Expression profiles of genes encoded by the supernumerary chromosome controlling AM-toxin biosynthesis and pathogenicity in the apple pathotype of Alternaria alternata. Mol Plant Microbe Interact 2007, 20:1463-1476.

50. Ma L-J, van der Does HC, Borkovich KA, Coleman JJ, Daboussi M-J, Di Pietro A, Dufresne M, Freitag M, Grabherr M, Henrissat B, Houterman PM, Kang S, Shim W-B, Woloshuk C, Xie X, Xu J-R, Antoniw J, Baker SE, Bluhm BH, Breakspear A, Brown DW, Butchko RAE, Chapman S, Coulson R, Coutinho PM, Danchin EGJ, Diener A, Gale LR, Gardiner DM, Goff S, et al: Comparative genomics reveals mobile pathogenicity chromosomes in Fusarium. Nature 2010, 464:367-373.

51. Friesen TL, Meinhardt SW, Faris JD: The Stagonospora nodorum-wheat pathosystem involves multiple proteinaceous host-selective toxins and corresponding host sensitivity genes that interact in an inverse genefor-gene manner. Plant J 2007, 51:681-692.

52. Ciuffetti LM, Manning VA, Pandelova I, Betts MF, Martinez JP: Host-selective toxins, Ptr ToxA and Ptr ToxB, as necrotrophic effectors in the Pyrenophora tritici-repentis-wheat interaction. New Phytologist 2010, 187:911-919.

53. Stergiopoulos I, de Wit PJGM: Fungal effector proteins. Annu Rev Phytopathol 2009, 47:233-263.

54. Tuori RP, Wolpert TJ, Ciuffetti LM: Purification and immunological characterization of toxic components from cultures of Pyrenophora tritici-repentis. Mol Plant Microbe Interact 1995, 8:41-48.

55. Martinez JP, Ottum SA, Ali S, Francl LJ, Ciuffetti LM: Characterization of the ToxB Gene from Pyrenophora tritici-repentis. Mol Plant Microbe Interact 2001, 14:675-677.

56. Liu Z, Faris JD, Oliver RP, Tan K-C, Solomon PS, McDonald MC, McDonald BA, Nunez A, Lu S, Rasmussen JB, Friesen TL: SnTox3 acts in effector triggered susceptibility to induce disease on wheat carrying the Snn3 gene. PLoS Pathog 2009, 5:e1000581

57. Friesen T, Chu CG, Liu Z, Xu S, Halley S, Faris J: Host-selective toxins produced by Stagonospora nodorum confer disease susceptibility in adult wheat plants under field conditions. Theor Appl Genet 2009, 118:1489-1497.

58. Kema GHJ, Goodwin SB, Hamza S, Verstappen ECP, Cavaletto JR, Van der Lee TAJ, de Weerdt M, Bonants PJM, Waalwijk C: A combined amplified fragment length polymorphism and randomly amplified polymorphism DNA genetic linkage map of Mycosphaerella graminicola, the Septoria tritici leaf blotch pathogen of wheat. Genetics 2002, 161:1497-1505.

59. Zhong S, Steffenson BJ, Martinez JP, Ciuffetti LM: A molecular genetic map and electrophoretic karyotype of the plant pathogenic fungus Cochliobolus sativus. Mol Plant Microbe Interact 2002, 15:481-492.

60. Nitta N, Farman ML, Leong SA: Genome organization of Magnaporthe grisea: integration of genetic maps, clustering of transposable elements and identification of genome duplications and rearrangements. Theor Appl Genet 1997, 95:20-32.

61. Pedersen C, Rasmussen SW, Giese H: A genetic map of Blumeria graminis based on functional genes, avirulence genes, and molecular markers. Fungal Genet Biol 2002, 35:235-246.

62. Steffenson BJ, Webster RK: Pathotype diversity of Pyrenophora teres $f$. teres on barley. Phytopathology 1992, 82:170-177.

63. Lai Z, Faris JD, Weiland JJ, Steffenson BJ, Friesen TL: Genetic mapping of Pyrenophora teres $\mathrm{f}$. teres genes conferring avirulence on barley. Fungal Genet Biol 2007, 44:323-329.

64. Bentley DR, Balasubramanian S, Swerdlow HP, Smith GP, Milton J, Brown CG, Hall KP, Evers DJ, Barnes CL: Accurate whole human genome sequencing using reversible terminator chemistry. Nature 2008, 456:53-59.

65. iVEC. [http://www.ivec.org/].

66. R Development Core Team: R: a Language and Environment for Statistical Computing Vienna: R Foundation for Statistical Computing; 2010.

67. Ter-Hovhannisyan V, Lomsadze A, Chernoff YO, Borodovsky M: Gene prediction in novel fungal genomes using an $a b$ initio algorithm with unsupervised training. Genome Res 2008, 18:1979-1990.

68. Eddy S: HMMER User's Guide. Biological Sequence Analysis Using Profile Hidden Markov Models, 2.3.2 2003

69. Krzywinski M, Schein J, Birol I, Connors J, Gascoyne R, Horsman D, Jones SJ, Marra MA: Circos: An information aesthetic for comparative genomics. Genome Res 2009, 19:1639-1645.

70. Li H, Durbin R: Fast and accurate short read alignment with BurrowsWheeler transform. Bioinformatics 2009, 25:1754-1760.

71. Wickham H: ggplot2: Elegant Graphics for Data Analysis. 2 edition. New York: Springer; 2009

72. Benson G: Tandem repeats finder: a program to analyze DNA sequences. Nucleic Acids Res 1999, 27:573-580

73. Rozen S, Skaletsky H: Primer3 on the WWW for general users and for biologist programmers. Methods Mol Biol 2000, 132:365-386.

74. Nourollahi K, Javannikkhah M, Naghavi MR, Lichtenzveig J, Okhovat SM, Oliver RP, Ellwood SR: Genetic diversity and population structure of Ascochyta rabiei from the western Iranian llam and Kermanshah provinces using MAT and SSR markers. Mycol Prog 2010.

75. Hayden M, Nguyen T, Waterman A, Chalmers K: Multiplex-ready PCR: A new method for multiplexed SSR and SNP genotyping. BMC Genomics 2008, 9:80

76. Quinlan AR, Hall IM: BEDTools: a flexible suite of utilities for comparing genomic features. Bioinformatics 2010, 26:841-842

77. Vos P, Hogers R, Bleeker M, Reijans M, Lee Tvd, Hornes M, Friters A, Pot J, Paleman J, Kuiper M, Zabeau M: AFLP: a new technique for DNA fingerprinting. Nucleic Acids Res 1995, 23:4407-4414.

78. Liu ZH, Anderson JA, Hu J, Friesen TL, Rasmussen JB, Faris JD: A wheat intervarietal genetic linkage map based on microsatellite and target region amplified polymorphism markers and its utility for detecting quantitative trait loci. Theor Appl Genet 2005, 111:782-794.

79. Zhong S, Leng Y, Friesen TL, Faris JD, Szabo LJ: Development and characterization of expressed sequence tag-derived microsatellite markers for the wheat stem rust fungus Puccinia graminis f. sp. tritici. Phytopathology 2009, 99:282-289.

80. Arie T, Christiansen SK, Yoder OC, Turgeon BG: Efficient cloning of Ascomycete mating type genes by PCR amplification of the conserved MATHMG box. Fungal Genet Biol 1997, 21:118-130.

81. Nelson JC: QGENE: software for marker-based genomic analysis and breeding. Mol Breed 1997, 3:239-245.

82. Voorrips RE: MapChart: software for the graphical presentation of linkage maps and QTLs. J Hered 2002, 93:77-78.

doi:10.1186/gb-2010-11-11-r109

Cite this article as: Ellwood et al:: A first genome assembly of the barley fungal pathogen Pyrenophora teres f. teres. Genome Biology 2010 11:R109.

\section{Submit your next manuscript to BioMed Central and take full advantage of:}

- Convenient online submission

- Thorough peer review

- No space constraints or color figure charges

- Immediate publication on acceptance

- Inclusion in PubMed, CAS, Scopus and Google Scholar

- Research which is freely available for redistribution 